\title{
Fatores socioculturais, mitos e crenças de nutrizes potenciais causadores do desmame precoce: uma revisão integrativa
}

\author{
Sociocultural factors, myths and beliefs of mothers potential causers of the early weaning: an integrative review \\ Factores socioculturales, mitos y creencias de las madres lactantes causas potenciales del destete precoz: una revisión \\ integradora
}

\begin{abstract}
RESUMO
Objetivo: Identificar fatores socioculturais de nutrizes relacionados à amamentação. Método: Trata-se de uma revisão integrativa realizada nas bases de LILACS, BDENF e IBECS. Foram utilizados os descritores "Crença", "Aleitamento Materno", "Amamentação" e "Nutriz" por meio do cruzamento com os operadores booleanos "AND" e "OR". Os artigos coletados foram selecionados pelo título, seguido da leitura do resumo e a leitura na íntegra. A lacuna temporal considerada na busca foi de 2009 a 2019. Resultados: Foram localizados oito artigos. Após aplicação dos critérios de inclusão, 04 artigos foram inclusos no estudo. Entre os fatores socioculturais destacam-se mitos e crenças, a falta de vontade ou preguiça de amamentar. Também influenciaram e geraram impacto direto na amamentação as crenças e a situação econômica, social e cultural das mulheres. Conclusão: Os fatores socioculturais relacionaram-se a interrupção precoce da amamentação. Destaca-se a importância e a necessidade do conhecimento desses fatores pelos profissionais de saúde para elaboração de estratégias a fim de reduzir o impacto negativo no processo de amamentação para o binômio mãe/bebê.
\end{abstract}

DESCRITORES: Crenças; Aleitamento Materno; Amamentação.

\section{ABSTRACT}

Objective: Identify sociocultural factors of mothers related to breastfeeding. Methodology: It is an integrative review carried out on the basis of LILACS, BDENF and IBECS. The descriptors "Belief", "Breastfeeding", "Breastfeeding" and "Nutriz" were used by crossing with the Boolean operators "AND" and "OR". The collected articles were selected by title, followed by the summary reading and the full reading. The time gap considered in the search was from 2009 to 2019 . Results: Eight articles were found. After applying the inclusion criteria, 04 articles were included in the study. Among the socio-cultural factors stand out myths and beliefs, the unwillingness or laziness to breastfeed. Women's beliefs and economic, social and cultural situation also influenced and had a direct impact on breastfeeding.. Conclusion: Sociocultural factors were related to early interruption of breastfeeding. It highlights the importance and the need for health professionals to know these factors in order to develop strategies in order to reduce the negative impact on the breastfeeding process for the mother / baby binomial.

DESCRIPTORS: Belief; Breast Feeding, Breastfeeding mother.

\section{RESUMEN}

Objetivo: Identificar factores socioculturales de las madres lactantes relacionados con la lactancia. Método: Se trata de una revisión integradora realizada sobre la base de LILACS, BDENF e IBECS. Los descriptores "Creencia", "Lactancia materna", "Lactancia materna" y "Nutriz" se utilizaron cruzando con los operadores booleanos "Y" y "O". Los artículos recopilados fueron seleccionados por título, seguido de la lectura resumida y la lectura completa. El intervalo de tiempo considerado en la búsqueda fue de 2009 a 2019. Resultados: Se encontraron ocho artículos. Tras aplicar los criterios de inclusión, se incluyeron en el estudio 04 artículos. Entre los factores socioculturales, se destacan mitos y creencias, la falta de voluntad o pereza para amamantar. Las creencias y la situación económica, social y cultural de las mujeres también influyeron e impactaron directamente en la lactancia maternal. Conclusión: Los factores socioculturales se relacionaron con la interrupción temprana de la lactancia materna. Destaca la importancia y la necesidad de que los profesionales de la salud conozcan estos factores para desarrollar estrategias que permitan reducir el impacto negativo en el proceso de lactancia materna para el binomio madre / bebé.

DESCRIPTORES: Creencias; Amamantamiento; Amamantamiento.

RECEBIDO EM: 16/08/2020 APROVADO EM: 25/08/2020 


\section{Aline Tavares Carvalho}

Graduada em Enfermagem pela Faculdade de Ciências da Saúde do Centro Universitário Ritter dos Reis (Uniritter). Enfermeira do Hospital da Brigada Militar de Porto Alegre.

ORCID: 0000-0003-4283-3230

\section{Luciana Medeiros Paungartner}

Enfermeira - Pós Graduação em UTI Geral e Gestão da Assistência Intensiva ao Paciente Crítico - Instituto Faveni. ORCID: 0000-0003-1983-1114

\section{Alexander de Quadros}

Mestre em Educação pela Pontifícia Universidade Católica do Rio Grande do Sul (PUCRS). Professor das Faculdades Integradas de Taquara (FACCAT). Presidente da Sociedade Brasileira de Enfermagem em Feridas e Estética (SOBENFeE/RS). Membro Diretor da Rede Brasileira de Enfermagem em Segurança do Paciente (REBRAENSP) Polo Porto Alegre.

ORCID: 0000-0002-3023-7514

\section{Morgana Thaís Carollo Fernandes}

Enfermeira. Pós-Doutoranda em Saúde da Criança pela Pontifícia Universidade Católica do Rio Grande do Sul (PUCRS), bolsista pela University of Toronto (UofT). Professora Colaboradora da Residência Multiprofissional em Saúde da Criança e Pesquisadora Associada do Programa de Extensão e Pesquisa em Saúde Urbana, Ambiente e Desigualdades da Universidade Federal do Rio Grande do Sul (UFRGS).

ORCID: 0000-0002-7989-294X

\section{Amanda Pereira Ferreira Dellanhese}

Enfermeira. Doutora em Saúde da Criança e do Adolescente pela Universidade Federal do Rio Grande do Sul. Docente Colaboradora da Residência Integrada Multiprofissional em Saúde Coletiva da Universidade Federal do Rio Grande do Sul.

ORCID: 0000-0002-1515-9693

\section{INTRODUÇÃO}

0 leite materno é o alimento ideal e essencial para os recém-nascidos nos primeiros meses de vida devido às suas propriedades nutricionais e imunológicas. Por esse motivo, o recomendado pelo Ministério da Saúde ${ }^{1}$ é que a nutriz mantenha o aleitamento materno exclusivo até os seis meses de idade do bebê e, pelo menos, até os dois anos de idade juntamente à alimentação complementar ${ }^{2}$.

A prática da amamentação protege a saúde do lactente, prevenindo o aparecimento de doenças características do início de vida, como infecções, doenças gastrointestinais e respiratórias, além de comorbidades crônicas como diabetes mellitus e alergias alimentares. $\mathrm{O}$ aleitamento materno pode evitar a morte de 823.000 crianças menores de 5 anos anualmente. 2 Além disso, reforça o vínculo do binômio mãe/bebể ${ }^{3}$.

Para a nutriz, pode reduzir o risco de desenvolvimento de câncer de útero ou ovários e fraturas3, previne a ocorrência do câncer de mama, podendo impedir a morte pela doença de até 20.000 mulhe- res anualmente. Entretanto, mesmo com os comprovados benefícios, o Brasil ainda não atinge as recomendações do Ministério da Saúde ${ }^{1}$ e o desmame precoce segue ocorrendo de maneira significativa, o que, consequentemente, eleva os índices de morbimortalidade infantil ${ }^{4}$.

Por esse motivo, o tema vêm sendo pauta de diversos programas governamentais, que objetivam elaborar estratégias de redução do desmame precoce. Para isso, devem ser considerados os aspectos biológicos e os socioculturais ${ }^{3}$. Os primeiros estão relacionados à integridade anatomofisiológica das mamas da nutriz e às condições do aparelho estomatognático do bebê, que garantem a ocorrência do processo de lactação e ejeção do leite, assim como boa pega e sucção correta. Já os socioculturais envolvem a cultura e o ambiente a qual a mulher e sua família estão inseridos, que podem impactar no processo de amamentaçãos.

Mitos sobre pouca produção de leite para saciar o bebê, a falta de vontade ou preguiça de amamentar, o baixo entendimento sobre a importância da amamen- tação, a volta à rotina de trabalho antes do bebê completar seis meses de vida, a preocupação com a estética dos seios após o desmame, a autopercepção corporal da mulher, o uso de chupetas ou mamadeiras com bicos artificiais e as crenças das pessoas de referência da nutriz influenciam na amamentação, e desmame precoce ${ }^{4}$.

O objetivo desse estudo foi revisar na literatura científica os fatores socioculturais de nutrizes relacionados a amamentação. Entende-se ser relevante explicitar estes aspectos presentes na vida da nutriz e refletir acerca do impacto que exercem no processo de amamentação, sendo possíveis causadores do desmame precoce.

\section{METODOLOGIA}

Trata-se de uma revisão integrativa da literatura de natureza descritiva. Para a realização do estudo, utilizou-se como base a pergunta norteadora: "Quais os fatores socioculturais da nutriz influenciam na amamentação?”. O estudo foi desenvolvido de março a dezembro de 2019. As bases de dados utilizadas foram: LILACS (litera- 
tura científica e técnica da América Latina e Caribe), BDENF (Banco de Dados em Enfermagem) e IBECS (Índice Bibliográfico Español en Ciencias de la Salud).

Foram utilizados os descritores "Crença", "Aleitamento Materno", "Amamentação" e "Nutriz" por meio do cruzamento com os operadores booleanos "AND" e "OR". Os artigos coletados foram selecionados pelo título, seguido da leitura do resumo e a leitura na íntegra. A lacuna temporal considerada na busca foi de 2009 a 2019. Foram considerados elegíveis todos os artigos originais disponíveis on-line que abordassem sobre o assunto, publicados nos últimos dez anos e com texto completo disponível em português. Foram excluídos artigos de revisão, experimentais, sem relevância com o tema e que não se enquadrassem nos critérios de inclusão.

\section{RESULTADOS}

A partir da estratégia de busca foram localizados oito estudos, após exclusão dos que não se enquadravam nos critérios de inclusão, quatro foram selecionados.
A sumarização dos artigos inclusão estão descritas no quadro 1. Observa-se que dois estudos foram publicados no ano de 2011. Vale destacar que os aspectos socioculturais estão relacionados ao ambiente e à cultura a qual a nutriz está inserida que muitas vezes geram impacto no processo de amamentação. Metade dos estudos analisados pontuou como principais crenças e mitos: "o leite pode secar", "a pouca produção de leite", "o leite é fraco" e "o leite não mata a sede do bebê".

Além dessas crenças, observou-se outros fatores como a falta de vontade ou preguiça de amamentar, a volta da mulher ao mercado de trabalho antes do bebê completar seis meses de idade, a preocupação excessiva com a estética dos seios após a amamentação, a falta de preparo ou conhecimento da importância do aleitamento materno, o uso de chupetas e mamadeiras, a influência das pessoas de referência da nutriz, como pais e avós, e os conselhos dados por eles enquanto ela está amamentando. Todos os fatores mencionados anteriormente, relatados pelas mulheres participantes do estudo, estiveram diretamente relacionados com o tempo de amamentação ou com a interrupção do aleitamento materno ${ }^{4}$.

Observou-se que muitas nutrizes modificam a alimentação durante a gravidez de acordo com suas crenças na tentativa de produzir mais leite, por acreditarem que podem não produzir leite suficiente para o bebể. Já Oliveira e colaboradores 6 constataram que os fatores econômicos e socioculturais da nutriz influenciam em sua dieta e, constantemente, fazem com que ela se prive de alimentos essenciais para a boa produção de leite materno. Os resultados evidenciaram que os aspectos socioculturais da nutriz influenciaram no desmame precoce do bebê. Sendo assim, constata-se que estes aspectos devem ser levados em consideração tanto quanto os fatores biológicos, a fim de diminuir os impactos negativos que exercem no processo de amamentação

\section{DISCUSSÃO}

Os benefícios do leite materno são comprovados tanto para o lactente quan-

\section{Quadro 1 - Distribuição dos artigos selecionados na revisão integrativa.}

\begin{tabular}{|c|c|c|c|}
\hline ESTUDO & DELINEAMENTO & OBJETIVO & PRINCIPAIS RESULTADOS \\
\hline $\begin{array}{l}\text { Nutr. clín. diet. hosp. } \\
\text { 2016; 36(4):27-334 }\end{array}$ & $\begin{array}{c}\text { Estudo transversal } \\
\text { descritivo. }\end{array}$ & $\begin{array}{l}\text { Analisar o conhecimento de gestantes no } \\
\text { pré-natal quanto a mitos/crenças relaciona- } \\
\text { dos ao aleitamento materno e sua influência } \\
\text { na intenção/duração. }\end{array}$ & $\begin{array}{l}\text { Os mitos e crenças citados foram: - leite se- } \\
\text { cou/seca; - leite materno não mata a sede do } \\
\text { bebê; - os seios caem com o aleitamento. }\end{array}$ \\
\hline $\begin{array}{l}\text { Ciência \& } \\
\text { Saúde Coletiva, } \\
\text { 16(10):4267-4274, } \\
\text { 2011² }\end{array}$ & $\begin{array}{c}\text { Pesquisa } \\
\text { qualitativa. }\end{array}$ & $\begin{array}{l}\text { Compreender os significados atribuídos } \\
\text { pelas mulheres ao hábito alimentar, no } \\
\text { que se referem às proibições, permissões } \\
\text { e lactogogos. }\end{array}$ & $\begin{array}{l}\text { Pensar em alimentação nesta fase } \\
\text { fisiológica implica conhecer os aspectos } \\
\text { histórico, social e cultural que interferem } \\
\text { na escolha alimentar, permitindo entender } \\
\text { hábitos e crenças para que a atuação } \\
\text { profissional seja focada no paciente. }\end{array}$ \\
\hline $\begin{array}{l}\text { Arquivos Brasilei- } \\
\text { ros de Ciências da } \\
\text { Saúde, v.36, n. 2, p. } \\
67-71, \text { Mai./Ago. } \\
2011^{6}\end{array}$ & Estudo transversal. & $\begin{array}{l}\text { Identificar as restrições alimentares às quais } \\
\text { se submetem às puérperas, acreditando } \\
\text { contribuir favoravelmente para a sua saúde } \\
\text { e a do bebê. }\end{array}$ & $\begin{array}{l}\text { Os dados encontrados apontaram para a exis- } \\
\text { tência de tabus e crenças com relação à ali- } \\
\text { mentação durante a lactação. }\end{array}$ \\
\hline $\begin{array}{l}\text { Revista de Salud } \\
\text { Pública, (XIII) 2: } \\
\text { 6-14, dic. 20097 }\end{array}$ & $\begin{array}{l}\text { Descritivo com } \\
\text { abordagem quali- } \\
\text { tativa }\end{array}$ & $\begin{array}{l}\text { Analisar os principais fatores, na percepção } \\
\text { da nutriz, que interferem na amamentação } \\
\text { exclusiva nos seis primeiros meses de vida } \\
\text { do lactente?. }\end{array}$ & $\begin{array}{l}\text { Excesso de trabalho doméstico, outros filhos, } \\
\text { trabalho externo; Mitos e crenças: "leite fraco, } \\
\text { não sustentar"; É de fundamental importância } \\
\text { que não se generalize à capacidade de ama- } \\
\text { mentar sem antes considerar o contexto que } \\
\text { o binômio está inserido. }\end{array}$ \\
\hline
\end{tabular}


to para a nutriz e sua família, porém a amamentação segue sendo interrompida precocemente e, consequentemente, eleva as taxas de morbimortalidade infantil. Diversos fatores estão relacionados a essa interrupção como fatores biológicos que permitem a produção e ejeção do leite materno, assim como pega e sucção corretas do bebê, os aspectos socioculturais relacionados ao ambiente e à cultura a qual a nutriz está inserida, e que em muitos casos são permeados aspectos socioculturais por crenças e mitos, falta de vontade ou preguiça de amamentar, a volta à rotina de trabalho, estética, uso de bicos artificiais, falta de preparo ou falta de conhecimento sobre aleitamento materno e influência de pessoas de referência da nutriz sobre o processo de amamentação ${ }^{3}$.

Os principais mitos relatados pelas nutrizes nos estudos são de que o leite pode secar, que produzem pouco ou que o mesmo é fraco, deixando-as inseguras quanto à nutrição do bebê. Esta insegurança, quando associada ao choro incessante do lactente tem tendência de gerar desconforto na mãe, induzindo ela a oferecer outros tipos de alimentos como água, chás ou fórmulas infantis precocemente ${ }^{4}$, entretanto, a hipogalactia não é um fenômeno recorrente nas nutrizes ${ }^{8}$. Muitas mulheres mudam sua alimentação de acordo com suas crenças na gravidez com o objetivo de produzir mais leite ${ }^{4}$.

Mesmo que nos tempos atuais as lactantes já possuam maior nível de conhecimento sobre os benefícios do aleitamento materno, os aspectos socioculturais ainda exercem influência na introdução de alimentos complementares antes da idade recomendada ${ }^{5}$. Conforme o Ministério da Saúdel a complementação deve ser inserida a partir dos seis meses de idade.

Aspectos como "falta de vontade ou preguiça de amamentar" também foram relatados pelas nutrizes, já que o aleitamento materno exige paciência e técnica, além de tempo e disposição delas perante as necessidades do bebê. A mãe não sente a amamentação como um gesto prazeroso ou não tem noção da importância dela para a saúde do recém-nascido, desistindo do aleitamento materno exclusivo antes que a criança complete seis meses de idade ${ }^{3}$.

\section{A influência dos}

familiares também

pode gerar impacto

negativo no período

de aleitamento

materno, já que esses

parentes pressionam

a nutriz a amamentar

o bebê de acordo

com suas percepções

ou conhecimento

sobre o assunto por

meio de conselhos

ou exemplos, ora

favoráveis, ora

contrários às

vontades dela.

Mesmo com os diversos direitos garantidos às mães trabalhadoras pela legislação brasileira, a volta à rotina de trabalho pode levar ao desmame precoce, já que a licença maternidade é oferecida pelo período de poucos meses. Com a nutriz trabalhando longe de casa ou por longos períodos, tendo que deixar o bebê em creches ou em outros locais distantes do seu local de trabalho, torna-se dificultoso que ela encontre o bebê nos intervalos previstos pela lei e coloque em prática a amamentação ${ }^{4}$.
Além disso, aponta-se o tópico a "estética ou vaidade", já que os mitos de que "os seios ficam flácidos" ou que " caem após um longo período de amamentação" geram desconforto na nutriz ao amamentar ${ }^{4}$. As mães geralmente não são orientadas sobre a queda das mamas estar associada à sustentação incorreta, ${ }^{10}$. É citado que a autopercepção corporal da mulher tanto na gravidez quanto no período de amamentação é um fator relevante, pois a insegurança com o corpo, a sensualização das mamas e o constrangimento podem desencorajar a decisão da mulher em manter o aleitamento materno ${ }^{6}$.

O uso de chupetas ou mamadeiras também pode reduzir o tempo de amamentação, já que a sucção do leite pelo bebê é facilitada por meio dos bicos artificiais e, quando ele é colocado de volta ao seio, percebe que a quantidade de leite sugada pela mama é menor do que pela mamadeira, levando ao desinteresse da criança pela amamentação ${ }^{11}$. As mães têm conhecimento de que o uso de chupetas e mamadeiras é inadequado, porém acreditam que acessórios auxiliam a acalmar o bebê e permitem que elas possam se dedicar a outras atividades ${ }^{12}$.

A influência dos familiares também pode gerar impacto negativo no período de aleitamento materno, já que esses parentes pressionam a nutriz a amamentar o bebê de acordo com suas percepções ou conhecimento sobre o assunto por meio de conselhos ou exemplos, ora favoráveis, ora contrários às vontades dela ${ }^{6}$. Verifica-se que opiniões negativas de pessoas próximas podem levar a mãe a ter uma percepção errada sobre a quantidade de leite que é capaz de produzir ${ }^{11}$.

A "a falta de preparo/conhecimento" foi o fator menos referido pelas mulheres, sendo este o mais compreensível como potencial causa do desmame precoce, já que o desconhecimento leva as pessoas a acreditarem em mitos mais do que em fatores comprovados cientificamente. Assim, torna-se evidente que o conhecimento da mãe sobre o assunto é um fator determinante na continuidade da prática da amamentação ${ }^{3}$. 
Além dos aspectos biológicos e socioculturais da nutriz, também deve ser considerado o nível de capacitação dos profissionais de saúde, pois nem sempre estão preparados para auxiliar sobre o assunto. Nessa perspectiva, a conduta do enfermeiro é fundamental, pois possui papel privilegiado no que diz respeito ao auxílio no processo de amamentação ${ }^{4}$ no pré-natal, pós-parto e puerpério. Ressalta-se que o enfermeiro precisa estar atento quanto as reais necessidades da nutriz e ter sensibilidade no que diz respeito à orientação sobre o aleitamento materno ${ }^{11}$.

Recentemente houve validação do conteúdo dos enunciados de diagnósticos, resultados e intervenções de enfermagem contidos no subconjunto termi- nológico da classificação internacional para a prática de enfermagem (CIPE) para auxiliar na assistência à nutriz, ao lactente e à família em processo de amamentação e dos 98 diagnósticos/resultados de enfermagem, 50 foram validados, e das 396 intervenções de enfermagem apresentadas, 350 receberam validação, mas $52 \%$ dos enunciados dos subconjuntos que foram validados estão relacionados com as condições biológicas, destacando-se três conceitos que não tiveram validação de seus enunciados: "imagem corporal da mulher", "percepção da criança sobre amamentação" e "autoridade familiar e social" 5 . Esse fato leva a reflexão de que embora avanços tenham ocorridos na assistência à nutriz ainda há desvalorização de abordagem e compromisso com as necessidades expressadas pelas nutrizes.

\section{CONCLUSÃO}

Os fatores socioculturais como mitos e crenças, mostraram-se grandes influenciadores negativos na prática da amamentação, sendo potenciais causadores do desmame precoce. É de suma importância a realização de estudos mais abrangentes sobre o assunto com o objetivo de desenvolver ações para melhorar a promoção, o incentivo e o apoio ao aleitamento materno. Assim, é essencial que os profissionais da saúde conheçam o contexto de vida, a cultura e o ambiente em que a nutriz está inserida, esclarecendo de forma efetiva suas angústias, dúvidas, medos e desmistificando crenças e mitos que estas carregam.

\section{REFERÊNCIAS}

1. BRASIL, Ministério da Saúde. Secretaria de Atenção à Saúde. Departamento de Ações Programáticas e Estratégicas. Área Técnica de Saúde da Criança e Aleitamento Materno. II Pesquisa de prevalência de aleitamento materno nas capitais brasileiras e Distrito Federal. 2009.

2. Vaucher, ALI; Durman, S. "Amamentação: crenças e mitos". In Rev Eletrônica de Enfermagem; 7(2):207- 214, 2005. VICTORA, C. $\mathrm{G}$. et al. Breastfeeding in the 21st century: epidemiology, mechanisms, and lifelong effect. The Lancet, [S.I.], v. 387, n. 10017, p. 475-489, 2016.

3. Marques, ES; Cotta, RMM; Priore, SE. Mitos e crenças sobre o aleitamento materno. Ciênc. saúde coletiva [Internet]. Maio de 2011 [citado em 14 de agosto de 2020]; 16 (5): 2461-2468. Disponivel em: http://www.scielo.br/scielo.php?script=sci_arttext\&pid=S1413-81232011000500015\&Ing=en. https://doi. org/10.1590/S1413-81232011000500015.

4. Lahós, NT; Pretto, ADB; Pastore, CA. Mitos e crenças acerca do aleitamento materno no estado do Rio Grande do Sul (Brasil). Nutr. clín. diet. hosp; 36(4): 27-33, 2016. tab. Disponivel em: https:// pesquisa.bvsalud.org/portal/resource/pt/ibc-158989. Acesso em: 23 julho. 2020.

5. Resende, FZ; Almeida, MVS; Leite, FMC; Brandão, MAG; Cubas, MR; Araújo, JL et al . Subconjunto terminológico da classificação internacional para a prática de enfermagem (CIPE $\left.{ }^{\circledR}\right)$ para assistência à amamentação: estudo de validação de conteúdo. Acta paul. enferm. [Internet]. 2019 Feb [cited 2020 Aug 14] ; 32( 1 ): 35-45.

6. Oliveira, DR; Gomes, PR; Bando, AMN; Gonçalves, SR. Crenças alimentares no aleitamento materno: um estudo entre gestantes e nutrizes atendidas em uma maternidade pública no município de São Paulo. Arq. Bras. Ciênc. Saúde; 36(2)ago. 2011. Disponível em:
http://bases.bireme.br/cgibin/wxislind.exe/iah/online/?IsisScrip$\mathrm{t}=\mathrm{iah} / \mathrm{iah}$.xis\&src=google\&base=LILACS\&lang=p\&nex tAction=lnk\&exprSearch=594943\&indexSearch=ID. Acesso em: 20 julho. 2020.

7. Queiroz, PS; Oliveira, LRB; Martins, CL . Elementos que interferem na amamantaçâo exclusiva: percepçoes de. Rev. salud pública (Córdoba); 13(2): 6-14, dez. 2009. Disponivel em: https://pesquisa. bvsalud.org/portal/resource/pt/lil-542112. Acesso em: 19 nov. 2019.

8. Frota, et al. "Conhecimento de mães acerca do aleitamento materno e complementação alimentar: pesquisa exploratória". In Online Brazilian Journal of Nursing, Niterói, v. 12, n. 1 Abr 2013.

9. Vaucher, ALI; Durman, S. "Amamentação: crenças e mitos". In Rev Eletrônica de Enfermagem; 7(2):207- 214, 2005. Victória, C. G. et al. Breastfeeding in the 21st century: epidemiology, mechanisms, and lifelong effect. The Lancet, [S.I.], v. 387, n. 10017, p. 475-489, 2016.

10. Andrade, FR; Costa, MCD; Delfino, S. Desafios do aleitamento materno em primíparas: a importância da assistência de enfermagem. Disponivel em: http://nippromove.hospedagemdesites.ws/ anais_simposio/arquivos_up/documentos/artigos/0a e64744b522349c55f02da50bb79d19.pdf. Acesso em: 16 nov. 2019.

11. Almeida, IS Ribeiro, IB; Rodrigues, BRD; Costa, CCP; Freitas, Natália,S; Vargas, EB. Amamentação para mães primíparas: perspectivas e intencionalidades do enfermeiro ao. Cogitare enferm; 15(1) jan.-mar. 2010.Disponível em: https://pesquisa.bvsalud.org/ portal/resource/pt/lil543929. Acesso em: 22 nov. 2019.

12. Marques, ES; Cotta, RMM; Araújo, RMA. "Representações sociais de mulheres que amamentam sobre a amamentação e o uso de chupeta". In Rev. Bras. Enferm. Brasília, v.62, n. 4, ago. 2009. 


\section{artigo}

Carvalho, A.T.; Paungartner, L.M.; Quadros, A.; Fernandes, M.T.C.; Dellanhese, A.P.F.;

Fatores socioculturais, mitos e crenças de nutrizes potenciais causadores do desmame precoce: uma revisão integrativa

\section{Fluxograma das etapas de seleção de artigos nas bases de dados LILACS, BDENF e IBECS.}

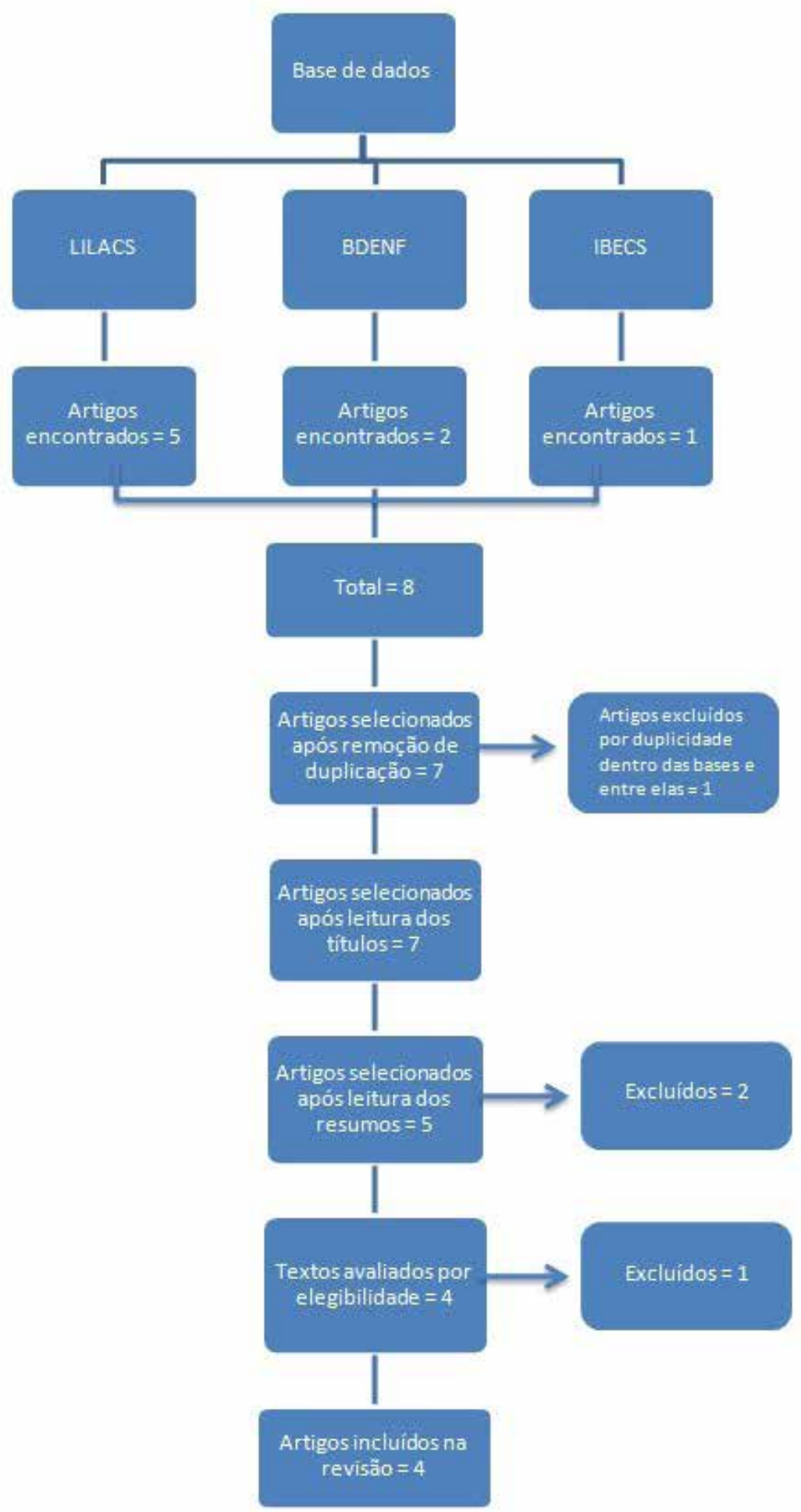

